\title{
Differential impact of osteoporosis, sarcopenia and obesity on physical performance in aging men
}

\author{
Franca Genest, Michael Schneider, Andreas Zehnder, Dominik Lieberoth-Leden and Lothar Seefried \\ Clinical Trial Unit, Orthopedic Department, University of Wuerzburg, Wuerzburg, Germany
}

Correspondence should be addressed to L Seefried: I-seefried.klh@uni-wuerzburg.de

\begin{abstract}
Purpose: Aging and concurrent constitutional changes as sarcopenia, osteoporosis and obesity are associated with progressive functional decline. Coincidence and mutual interference of this risk factors require further evaluation.

Methods: Cross-sectional evaluation of musculoskeletal health in a community-dwelling cohort of men aged 65-90 years. Objectives included descriptive analysis of age-related decline in physical performance, prevalence of osteoporosis (FRAX-Score), sarcopenia (EWGSOP criteria) and obesity (BMI $>30 \mathrm{~kg} / \mathrm{m}^{2}$ ) and their coincidence/interference. Results: Based on 507 participants assessed, aging was associated with progressive functional deterioration, regarding power (chair rise test $-1.54 \%$ per year), performance (usual gait speed $-1.38 \%$ per year) and muscle force (grip strength $-1.52 \%$ per year) while muscle mass declined only marginally (skeletal muscle index $-0.29 \%$ per year). Prevalence of osteoporosis was $41.8 \%(n=212)$ while only $22.9 \%(n=116)$ of the participants met the criteria for sarcopenia and $23.7 \%(n=120)$ were obese. Osteosarcopenia was found in $n=79$ (15.6\%), sarcopenic obesity was present in 14 men (2.8\%). A combination of all three conditions could be confirmed in $n=8(1.6 \%)$. There was an inverse correlation of BMI with physical performance whereas osteoporosis and sarcopenia did not interfere with functional outcomes.

Conclusion: Based on current definitions, there is considerable overlap in the prevalence of osteoporosis and sarcopenia, while obesity appears to be a distinct problem. Functional decline appears to be associated with obesity rather than osteoporosis or sarcopenia. It remains to be determined to what extend obesity itself causes performance deficits or if obesity is merely an indicator of insufficient activity eventually predisposing to functional decline.
\end{abstract}



Endocrine Connections (2021) 10, 256-264

\section{Introduction}

Aging is associated with progressive physical deficits showing a wide range of inter-individual variability. Loss of bone and muscle mass are associated with fracture risk and a decline in physical function which in turn causes reduced mobility and adverse outcomes including progressive disability and increased mortality $(1,2,3,4)$. Along with reduced muscle mass, deficient physical performance is a hallmark of sarcopenia, and the annual loss in mass and performance was reported to be around $1-2 \%$ and 3\%, respectively in men $>60$ years. Furthermore, a combination of sarcopenia with osteoporosis or obesity was assumed to worsen that effect $(5,6)$. The combination of sarcopenia and low $\mathrm{BMD}$ reflected in the term osteosarcopenia is considered

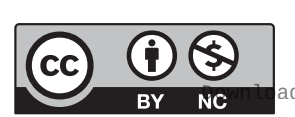

This work is licensed under a Creative Commons Attribution-NonCommercial 4.0 International License. ded from Bioscientifica.com at 04/26/2023 09:56:20AM 
to potentiate the risk for fractures and functional decline $(7,8,9,10,11)$ and both conditions are associated with similar risk factors $(3,7,12,13)$. Specifically, overweight and obesity are well-recognized to have a negative impact on physical capabilities and fracture risk $(14,15)$, although data regarding BMD and certain fracture types is heterogeneous $(16,17)$. Gain in fat mass and particularly increased visceral fat was shown to have a negative effect on BMD and bone structure and specifically hip fracture risk $(18,19,20,21)$. In addition, there might be an association between higher BMI and fracture risk beyond $\mathrm{BMD}$, particularly in the context of reduced physical performance ultimately leading to an elevated risk for falls and fractures $(18,20,22)$. Obesity and high BMI in turn are associated with increased muscle mass (23), suggesting lower prevalence of sarcopenia, while from a functional perspective, obesity also affects muscle quality and function, leading to fatty infiltration of muscles (24, $25,26)$. The combination of low muscle mass and poor function in association with obesity as described by the term 'sarcopenic obesity' is supposed to elevate falls and fracture risk, particularly in men (6).

Considering these associations of osteosarcopenia and sarcopenic obesity with functional limitations in the aging population, specifically in men, we aimed at identifying prevalence of osteoporosis, sarcopenia and obesity in aging men in order to evaluate how each one of these correlates with functional deficits, to what extend there is an overlap of these three conditions in terms of osteosarcopenia and sarcopenic obesity and if a constellation of supposed 'osteosarcobesity' or 'sarcoporobestiy' was a realistic worst-case scenario.

\section{Materials and methods}

\section{Study design and participants}

This is a cross-sectional evaluation of a general populationderived cohort of elderly men. Based on information obtained from the registration office, all men aged 65 to 90 years from two distinct post code areas of the German city of Wuerzburg were contacted by letter mail, asked to complete a questionnaire and to volunteer for a comprehensive musculoskeletal assessment.

\section{Osteoporosis and fracture risk}

Osteoporosis was determined by calculating individual fracture risk with the FRAX®-tool
(European, German Edition). Risk factors included in the assessment were age, sex, weight, height, previous fractures, parental hip fracture, smoking, use of glucocorticoids, rheumatoid arthritis, any form of secondary osteoporosis and alcohol abuse. Owing to national radiation protection regulations, BMD assessment was not consistently available and consequently not included in this calculation. Cut-off for osteoporosis was defined as a risk for sustaining a major osteoporotic fracture (MOF) $\geq$ $20 \%$ or an osteoporotic hip fracture (HOF) $\geq 3 \%(27,28)$.

\section{Body composition}

Evaluation of body composition included body weight, height and bioelectrical impedance analysis (BIA, BIA 101 Anniversary, Akern srl, Florence, Italy). Skeletal Muscle Index (SMI) was calculated using the pre-established formula for the respective device $(29,30)$. Individuals with reduced muscle mass were identified according to the EWGSOP threshold for sarcopenia (31), that is, low muscle mass was defined by an $\mathrm{SMI} \leq 10.75 \mathrm{~kg} / \mathrm{m}^{2}$. Obesity was defined using the WHO BMI cutoff at $\geq 30 \mathrm{~kg} / \mathrm{m}^{2}$.

\section{Physical performance}

Assessment of physical performance is based on the three items of the Short Physical Performance Battery (SPPB) $(31,32)$, consisting of a balance test, a $4 \mathrm{~m}$ usual gait speed and the chair rise test. In line with established literature, participants attaining 8 points or less in the SPPB were considered as having deficient physical performance.

\section{Strength}

Hand grip strength was measured for both hands by side-alternating testing in three cycles with a handheld dynamometer (DynEx1, Akern srl, Florence, Italy) in a seated position, the elbow flexed at 90 degrees. Best performance value was used for further analyses. The cutoff for reduced hand grip strength was set at $<30 \mathrm{~kg}$ for men (31). Sarcopenia was defined according to applicable EWGSOP criteria including low muscle mass (SMI) combined with at least one of the following two criteria, reduced strength based on handheld dynamometry or/and reduced physical performance based on SPPB (31).

\section{Statistical analysis}

Descriptive statistical analysis comprised absolute frequencies and corresponding proportions, arithmetic 
means and respective variation measures. Exploratory correlation analyses were calculated using Pearson's correlation coefficient. Between-group differences were assessed using independent samples t-tests. $P$ values of less than 0.05 were considered statistically significant. Log regression was used to estimate potential risk factors. All statistical analyses were performed using SPSS ver. 25 statistical software package (SPSS Inc.).

The study protocol was approved by the competent ethics committee at Wuerzburg University (N. 148/13) and registered with the German register for clinical studies (DRKS00013261). Informed consent was obtained from all individual participants included in the study.

\section{Results}

\section{Baseline data and characterization of the cohort}

Out of $n=2605$ men aged 65 to 90 years initially contacted by letter mail, $n=1107$ (42.5\%) returned the attached questionnaire providing baseline information on their age, height and weight. Out of these, $n=787$ indicated their willingness to attend the comprehensive musculoskeletal health assessment. In line with the case number pre-specified in the study protocol, $n=507$ men were invited and examined on a first-come-first-served basis (Fig. 1).

Mean age of these 507 participants was 74.7 years (s.D. 6.08 years), average height and weight were $174 \mathrm{~cm}$ (S.D. $6.51 \mathrm{~cm}$ ) and $84.8 \mathrm{~kg}$ (S.D. $13.3 \mathrm{~kg}$ ), respectively, yielding an average BMI of $28.0 \mathrm{~kg} / \mathrm{m}^{2}$ (s.D. $3.93 \mathrm{~kg} / \mathrm{m}^{2}$ ).
For assessing age-associated changes, participants were categorized into five different age groups, each covering 5 years. Participants' baseline characteristics and distribution over different age groups are summarized in Table 1.

\section{Physical performance}

With increasing age, there was a trend to reduced height and weight along with a significant decrease in both SMI $(P=0.004)$, fat free mass $(\mathrm{FFM})(P<0.001)$ and fat mass (FM) $(P=0.008)$, while BMI did not change significantly $(P=0.064)$. Regarding functional assessments, there was a significant decline with aging in all parameters of physical performance. Specifically, average usual gait speed reduced from $1.56 \mathrm{~m} / \mathrm{s}$ for the $65-69$ year old to $1.13 \mathrm{~m} / \mathrm{s}$ for those $\geq 85$ years $(P<0.001)$. In parallel, average time to perform the chair rise test continuously increased from $8.54 \mathrm{~s}$ in the 65-69 year group to $12.34 \mathrm{~s}$ in the $\geq 85$ year cohort $(P<0.001)$. The average SPPB-score decreased progressively starting from 11.7 points for the 65-69 year group to 9.5 points in the $\geq 85$ year old $(P<0.001)$. Hand grip strength declined significantly from 37.3 to $26.0 \mathrm{~kg}(P<0.001)$. Fracture risk for both major osteoporotic fractures and hip fractures increased progressively with aging.

The decline from the youngest to the oldest age group amounted to $5.8 \%$ for average SMI while deterioration of physical performance as assessed by the SPPB over the same age categories was $18.8 \%$. Age associated deterioration of physical performance became most obvious assessing usual gait speed, hand grip strength, and time to perform

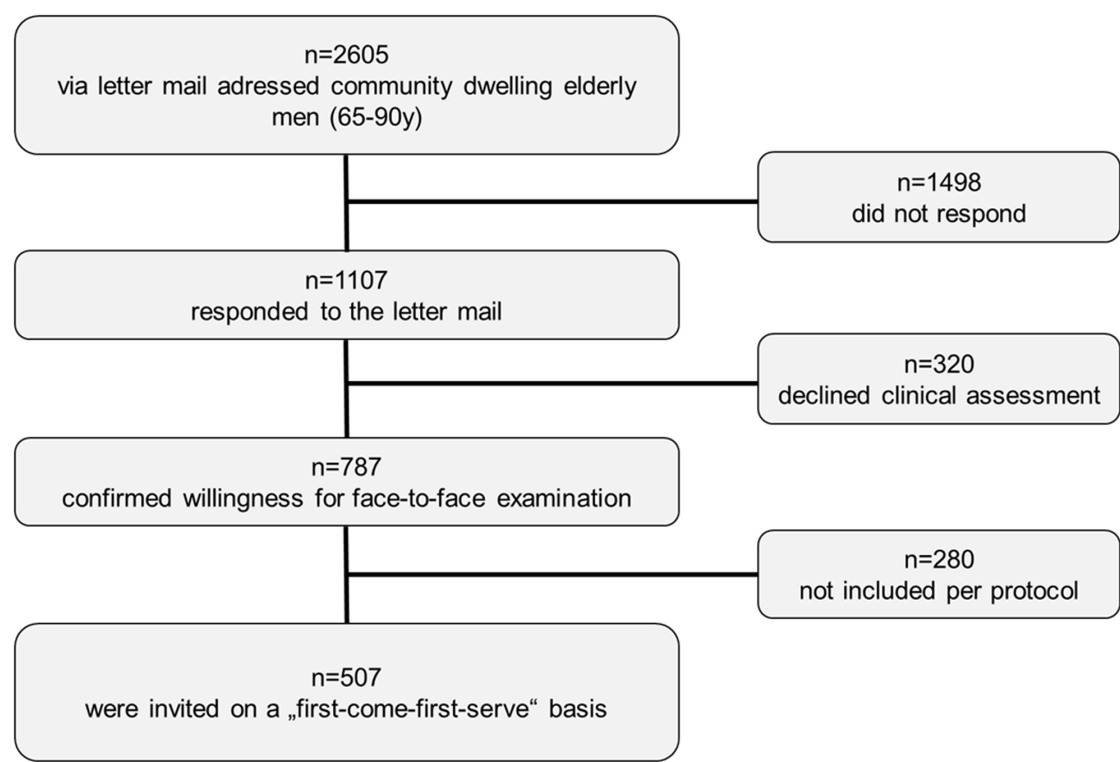

Figure 1

Study population flow. 
Table 1 Participants' characteristics for different age group (mean \pm S.D.).

\begin{tabular}{l}
\hline Age groups \\
\hline$n(\%)$ \\
Age (years) \\
Height $(\mathrm{cm})$ \\
Weight $(\mathrm{kg})$ \\
BMI $\left(\mathrm{kg} / \mathrm{m}^{2}\right)$ \\
Skeletal muscle index $\left(\mathrm{kg} / \mathrm{m}^{2}\right)$ \\
Fat mass $(\mathrm{kg})$ \\
Fat free mass $(\mathrm{kg})$ \\
Major osteoporotic fractures $(\%)$ \\
Osteoporotic hip fractures $(\%)$ \\
Usual gait speed (m/s) \\
Chair rise test (s) \\
Short physical performance \\
battery (points) \\
Hand grip strength $(\mathrm{kg})$
\end{tabular}

\begin{tabular}{c}
\hline All $(65-90$ years $)$ \\
\hline $507(100)$ \\
$74.7 \pm 6.08$ \\
$174 \pm 6.51$ \\
$84.8 \pm 13.3$ \\
$28.0 \pm 3.9$ \\
$10.2 \pm 1.03$ \\
$24.3 \pm 7.43$ \\
$59.9 \pm 7.29$ \\
$6.24 \pm 2.86$ \\
$3.11 \pm 2.26$ \\
$1.40 \pm 0.40$ \\
$9.93 \pm 4.01$ \\
$11.1 \pm 1.69$ \\
$33.2 \pm 7.30$ \\
\hline
\end{tabular}

\begin{tabular}{r}
\hline $\mathbf{6 5 - 6 9}$ years \\
\hline $112(22.1)$ \\
$67.1 \pm 1.39$ \\
$177 \pm 6.03$ \\
$87.2 \pm 12.7$ \\
$27.9 \pm 3.78$ \\
$10.4 \pm 1.01$ \\
$25.1 \pm 7.44$ \\
$61.8 \pm 6.80$ \\
$4.33 \pm 1.54$ \\
$1.44 \pm 0.99$ \\
$1.56 \pm 0.46$ \\
$8.54 \pm 2.40$ \\
$11.7 \pm 1.00$ \\
$37.3 \pm 7.16$
\end{tabular}

the chair rise test reducing by $27.6,30.3 \%$ and $30.8 \%$, respectively. Considering that the study cohort spanning roughly 20 years from the youngest to the oldest age group, the annual decline in skeletal muscle index is only $0.29 \%$ while the annual reduction in usual gait speed was $1.38 \%$, the loss in hand grip strength was $1.52 \%$ and the performance loss regarding CRT in men was as high $1.54 \%$, see also Fig. 2.

\section{Constitutional decline}

Across the different age groups, there was a statistical significant annual decline in weight $(0.53 \mathrm{~kg} /$ year $)$ with

\begin{tabular}{|c|c|c|c|c|}
\hline 70-74 years & 75-79 years & 80-84 years & $85-90$ years & P-values \\
\hline 160 (31.6) & $127(25.0)$ & 69 (13.6) & 39 (7.7) & \\
\hline $72.0 \pm 1.44$ & $77.0 \pm 1.48$ & $81.9 \pm 1.48$ & $86.9 \pm 1.59$ & $<0.001$ \\
\hline $174 \pm 6.56$ & $174 \pm 6.22$ & $172 \pm 6.08$ & $170 \pm 6.01$ & $<0.001$ \\
\hline $84.5 \pm 13.4$ & $86.7 \pm 14.0$ & $82.2 \pm 12.8$ & $76.6 \pm 8.34$ & $<0.001$ \\
\hline $27.9 \pm 4.05$ & $28.7 \pm 4.33$ & $27.7 \pm 3.37$ & $26.6 \pm 3.08$ & 0.064 \\
\hline $10.3 \pm 1.07$ & $10.2 \pm 1.10$ & $9.92 \pm 0.81$ & $9.80 \pm 0.76$ & 0.004 \\
\hline $24.0 \pm 7.18$ & $25.7 \pm 8.04$ & $22.2 \pm 6.74$ & $21.7 \pm 6.11$ & 0.008 \\
\hline $60.0 \pm 7.61$ & $60.2 \pm 7.62$ & $57.4 \pm 6.36$ & $55.8 \pm 4.88$ & $<0.001$ \\
\hline $5.29 \pm 1.71$ & $6.60 \pm 2.16$ & $8.88 \pm 3.46$ & $9.86 \pm 3.48$ & $<0.001$ \\
\hline $2.28 \pm 1.01$ & $3.55 \pm 1.62$ & $5.31 \pm 2.82$ & $6.09 \pm 2.87$ & $<0.001$ \\
\hline $1.48 \pm 0.39$ & $1.36 \pm 0.36$ & $1.20 \pm 0.27$ & $1.13 \pm 0.37$ & $<0.001$ \\
\hline $9.20 \pm 3.67$ & $10.7 \pm 4.02$ & $11.1 \pm 4.10$ & $12.3 \pm 6.30$ & $<0.001$ \\
\hline $11.5 \pm 1.17$ & $10.9 \pm 1.52$ & $10.3 \pm 2.10$ & $9.5 \pm 2.85$ & $<0.001$ \\
\hline $34.6 \pm 6.19$ & $32.0 \pm 6.85$ & $29.2 \pm 6.34$ & $26.0 \pm 5.14$ & $<0.001$ \\
\hline
\end{tabular}

only one third $(0.17 \mathrm{~kg} /$ year $)$ accounting for loss of fat mass. In parallel, there was also a significant decline in height $(0.35 \mathrm{~cm} /$ year$)$. As a consequence, BMI did not change significantly across the different age groups.

\section{Prevalence of reduced muscle mass and sarcopenia}

Reduced muscle mass defined by an SMI of $\leq 10.75 \mathrm{~kg} / \mathrm{m}^{2}$ was detected in $n=330$ (65.1\%) participants, while 166 $(32.7 \%)$ had reduced hand grip strength $(<30 \mathrm{~kg})$; an SPPB-Score $\leq 8$ was prevalent in $43(8.5 \%)$ participants.

Out of the 330 with reduced muscle mass, 107 exhibited reduced hand grip strength $(<30 \mathrm{~kg})$ and only 21 showed

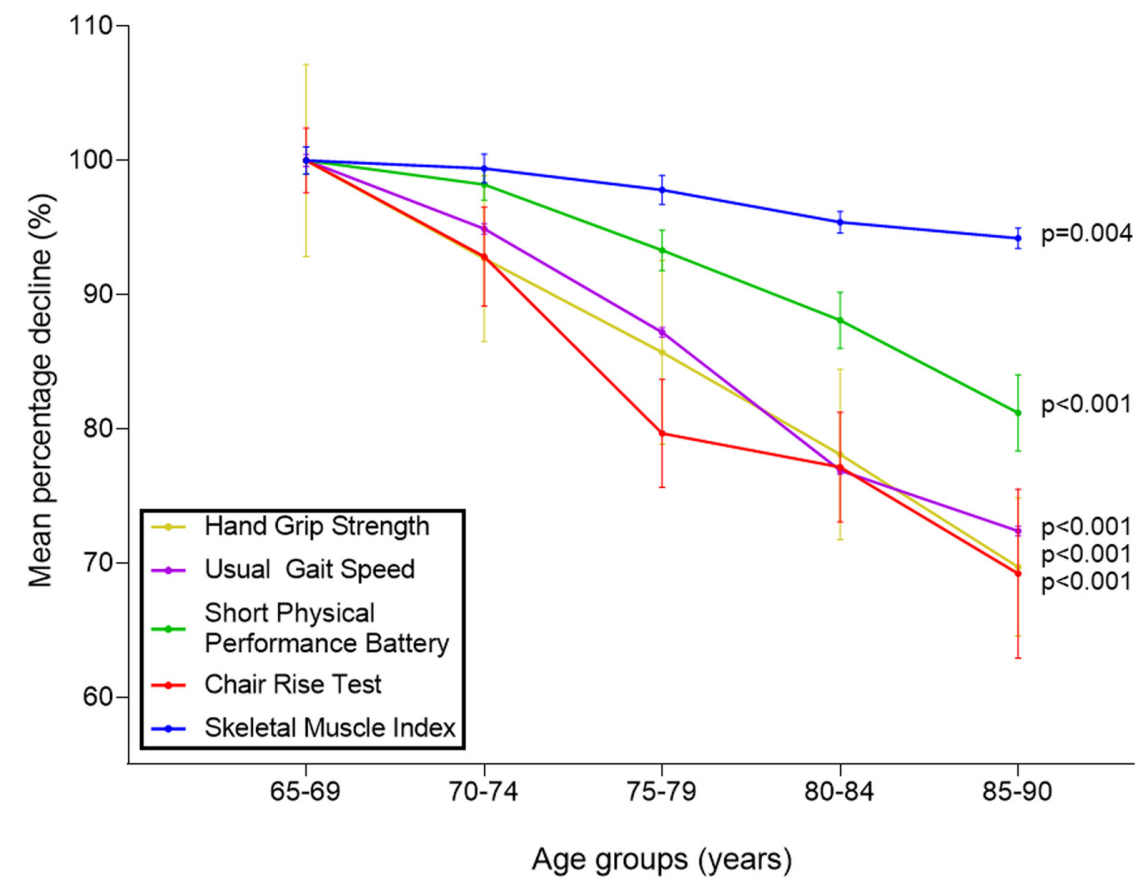

Figure 2

Constitutional and functional mean percentage decline with progressive aging for chair rise test, SMI, SPPB, hand grip strength and usual gait speed with S.D. Average results attained by the youngest age group (65-69 years) are defined as baseline $/ 100 \%$. Increase in time required to perform the chair rise test is depicted inversely to illustrate percentage decline according to the formula chair rise test percentage $=($ baseline $(\mathrm{s}) /$ time of respective age group $(\mathrm{s})) \times 100$. 
reduced physical performance (SPPB score $\leq 8$ ). Twelve participants exhibited deficits in both SPPB and hand grip strength. Taken together, sarcopenia was diagnosed in 116 participants (22.9\%) with low SMI and at least one of the two functional limitations. The proportion of sarcopenic participants progressively increased with age, applying to $50.9 \%(n=28)$ of participants in the 80-84 years group and to $71.0 \%(n=22)$ in the $85-90$ years group.

\section{Prevalence of obesity}

Applying WHO criteria for obesity, 120 out of the 507 participants $(23.7 \%)$ had a BMI $\geq 30 \mathrm{~kg} / \mathrm{m}^{2}$. While the proportion of obese subjects was around $25 \%$ of participants across all age groups from 65 to 79 years, there was a considerable decline to $18.8 \%$ in the $80-84$ years old and to as few as $10.5 \%$ in the $85-90$ years old. Average age of obese subjects was 73.9 years. Out of these 120 obese men, $n=28$ (5.5\%) had an SMI $\leq 10.75 \mathrm{~kg} / \mathrm{m}^{2}$, $n=44(8.7 \%)$ had reduced hand grip strength $<30 \mathrm{~kg}$ and $n=17(3.4 \%)$ had SPPB scores $\leq 8$.

Average results attained by the youngest age group (65-69 years) are defined as baseline/100\%. Increase in time required to perform the chair rise test is depicted inversely to illustrate percentage decline according to the formula chair rise test percentage $=($ baseline $(\mathrm{s}) /$ time of respective age group (s) $) \times 100$.

\section{Prevalence of osteoporosis}

According to FRAX criteria, 212 (41.8\%) participants had a $\geq 3 \% 10$ years probability of sustaining a HOF.
Out of these, $n=2(0.4 \%)$ additionally had a $\geq 20 \% 10$-year probability of sustaining a MOF. Since all participants with an increased risk for a MOF also had an increased risk for a HOF, these 212 represent the group of osteoporotic patients. The proportion of osteoporotic subjects increased with age from $7.1 \%$ in the $65-69$ years group to as many as $94.2 \%$ in the $80-84$ years old and $97.4 \%$ in the 85-90 years old. Average age of those at high fracture risk was 79.4 years.

\section{Overlap in prevalence of distinct risk factors}

Taken together, 336 (66.3\%) participants had at least one of the three conditions, namely osteoporosis, sarcopenia and obesity. Matching datasets of these 212 men with osteoporosis with those of the 120 men who were obese and the 116 datasets of sarcopenic men revealed that 79 (15.6\%) participants were affected by both sarcopenia and osteoporosis (osteosarcopenia) whereas sarcopenic obesity, that is, a coincidence of sarcopenia and obesity was prevalent in only $14(2.8 \%)$ subjects. In line with that, obese participants had significantly higher SMI $(P<0.001)$ across all age groups. Coincidence of osteoporosis and obesity (osteoporobesity) was detected in only 27 (5.3\%) participants, which is conceivable, considering that anticipated fracture risk for $\mathrm{HOF} / \mathrm{MOF}$ according to FRAX was significantly lower in men with an elevated BMI $\geq 30 \mathrm{~kg} / \mathrm{m}^{2}(P<0.001)$. Going one step further, an overlap of all three disorders, that is, a condition which could be designated osteosarcobesity or sarcoporobesity was present in only 8 participants (1.6\%) (Fig. 3).

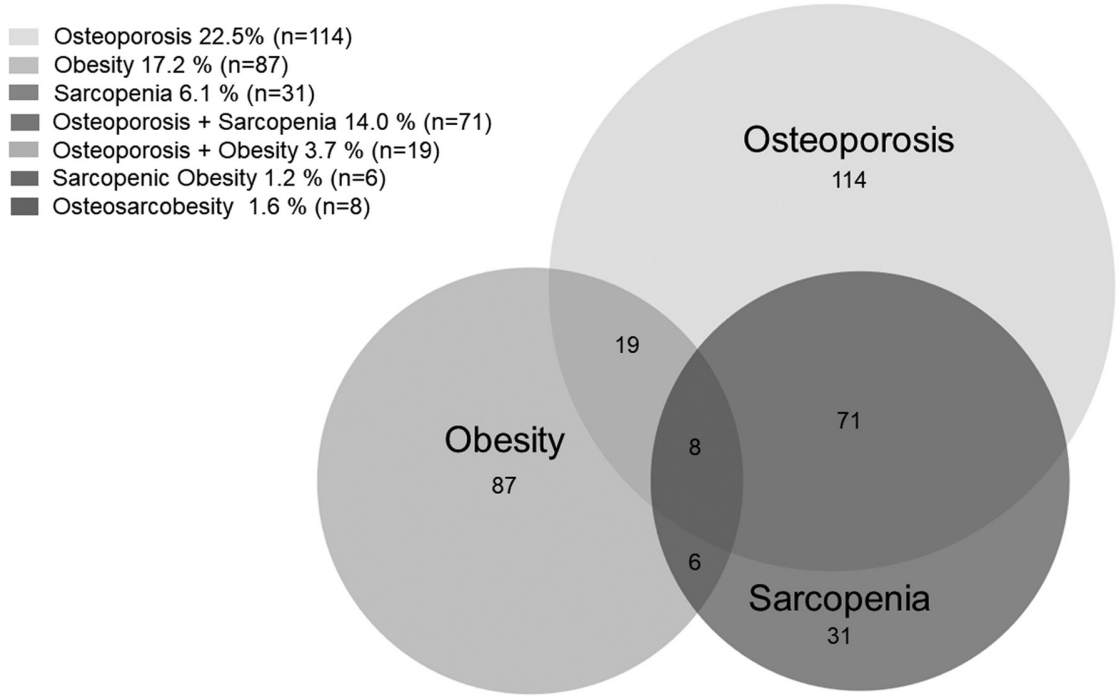

Figure 3

Coincidence and overlap of the three conditions osteoporosis, sarcopenia and obesity with absolute and percentage numbers of each condition in the figure legend.
This work is licensed under a Creative Commons Attribution-NonCommercial 4.0 International License. ded from Bioscientifica.com at 04/26/2023 09:56:20AM via free access 




Figure 4

Decline in SPPB overall score with $\mathrm{Cl}$ with increasing age according to BMI.

Impact of different conditions on

physical performance

\section{Differences in physical constitution and performance}

Subgroup analyses revealed that SPPB scores of obese participants at younger age ( $\leq 74$ years) were not different to those attained by the non-obese, while at higher age, obese participants experienced a more rapid decline than the rest of the cohort (Fig. 4). This finding appliedto the SPPB in general $(P=0.003)$ (Fig. 4) as well as to the individual tasks usual gait speed $(P<0.001)$ and chair rise test $(P=0.006)$. In contrast, hand grip strength was not significantly different in obese men as compared to the rest of the cohort $(P=0.463)$ across all age groups.

Osteoporotic men also exhibited worse physical performance with significantly inferior results regarding hand grip strength, usual gait speed and chair rise test as well as overall SPPB score $(P<0.001)$. Sarcopenic men attained significantly inferior results regarding the SPPB and the single items usual gait speed and chair rise test, and they exhibited significantly lower hand grip strength specifically in the younger age groups $\leq 79$ years $(P<0.001)$. However, this didn't appear to be a matter of reduced muscle mass, and physical performance measures including usual gait speed, chair rise test and SPPB were not significantly reduced in participants with an $\mathrm{SMI} \leq 10.75 \mathrm{~kg} / \mathrm{m}^{2}$. In contrast, there was even a nonsignificant $(P=0.061)$ trend to improved usual gait speed with lower SMI.

\section{Risk factors for decline of physical performance}

Logistic regression analysis was conducted in order to evaluate risk factors for reduced physical performance and strength in elderly men. Major risk factors for a reduced SPPB score $\leq 8$ were the prevalence of osteoporosis $(P=0.020)$, reduced hand grip strength $<30 \mathrm{~kg}(P=0.016)$ and an elevated BMI $\geq 30 \mathrm{~kg} / \mathrm{m}^{2} \quad(P=0.002)$, while age $\geq 80$ years $(P=0.313)$ and a reduced $S M I \leq 10.75 \mathrm{~kg} / \mathrm{m}^{2}$ $(P=0.722)$ did not have a significant impact. In addition, reduced usual gait speed $<0.8 \mathrm{~m} / \mathrm{s}$ was not a significant risk factor for reduced hand grip strength.

\section{Discussion}

Aging is associated with progressive constitutional changes, specifically involving bone, muscle, and fat tissue. Not only do these tissues account for the vast majority of human body mass, they also form the structural fundament of our musculoskeletal system and its functionality. It is therefore conclusive that ageassociated deterioration and disorders of these tissues, namely osteoporosis, sarcopenia and obesity result in functional decline of the musculoskeletal system. This study aimed at contributing to the growing understanding of the multifaceted interaction, coincidence and mutual interference of these conditions and their respective impact on individual patients' performance and functional capabilities.

In order to have a representative, homogenous cohort and to limit bias caused by individually different health awareness and health care access as well as environmental factors and gender-aspects, a geographically defined group of men were recruited from the general population. Concurrently, this approach also implies certain limitations that have to be considered when interpreting these findings. Owing to national restrictions regarding protection of radiation exposure, we could not conduct DXA measurements in all participants and so evaluation of fracture risk and osteoporosis is merely based on FRAX assessment devoid BMD data. By default, persons living in senior residences and other care facilities were not included. Accordingly, participants in this study may be comparatively healthy. Furthermore, the results cannot uncritically be transferred to females since gender aspects may have a strong and complex impact on musculoskeletal associated aging and even comparative scientific data in that regard is scarce.

Overall prevalence of osteoporosis, obesity and sarcopenia in this population-based cohort of elderly men was remarkably high with two third (66.3\%) being affected by at least one of these conditions. While osteoporosis

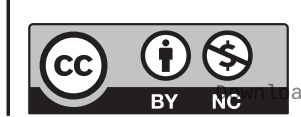

This work is licensed under a Creative Commons Attribution-NonCommercial 4.0 International License. ded from Bioscientifica.com at 04/26/2023 09:56:20AM 
was most frequent, affecting $41.8 \%(n=212)$ of all participants, data also confirm a considerable proportion of men meeting established criteria for sarcopenia (22.9\%, $n=116)$ and obesity $(23.7 \%, n=120)$. A relevant overlap with coincidence of two of these conditions was specifically seen for increased fracture risk and sarcopenia (i.e. osteosarcopenia), applying to 79 men (15.6\%) in line with current literature data ranging from 5 to $37 \%$ in community dwelling adults of $\geq 65$ years (33). Potential explanations specifically include established common risk factors for both conditions, particularly low body mass and aging itself (34). In contrast, the proportion of obese men appeared quite stable at around one quarter across the different age groups $<80$ years and declined in the higher age groups to only $10.3 \%$ in those $\geq 85$ years. In line with current literature questioning the so-called obesity paradox, it appears reasonable to conclude that a relevant proportion of obese men may have lost their selfsufficiency or may even have deceased before attaining that age (35). In addition, aging is associated with chronic low grade inflammation, commonly termed 'inflammaging' (36). This aging process is associated with a redistribution of body fat, most notably a reduction of appendicular, mostly s.c. fat and an increase in trunk/mainly abdominal fat and also an accumulation of fat tissue within organs, including muscles and these mechanisms may have contributed to our findings of a proportionally lower loss of muscle mass as compared to the decline in fat mass (37). In that regard, it is one of the shortcomings of our study and constitutional assessments in daily practice that routine BIA as included here may not appropriately reflect this redistribution and with fatty infiltration of muscles and indeed, only very recently a technical algorithm with serial BIA and a multifrequency bioimpedance device was proposed to make up for this deficit (38). In addition, data presented we don't have longitudinal data of exactly the same individuals to reflect individual changes of body composition and work out to what extend the changes observed may be biased by technical limitation or altered group composition in the very old.

Coincidence of obesity with osteoporosis (i.e. osteoporobesity) or sarcopenia (i.e. sarcopenic obesity) was only observed in 27 (5.3\%) and 14 (2.8\%) subjects, respectively. The low level of coincidence of these conditions is partially by definition, considering high BMI and to some degree aging being opposing risk factors for obesity vs sarcopenia and osteoporosis (39). Interestingly, omitting the BMI associated aspect of low SMI from the definition of sarcopenia and merely focusing on functional deficits, the overlap with regards to what may be called dynamopenic obesity was much more frequent. Out of 120 subjects with a BMI $\geq 30$, almost two thirds $(n=79)$ couldn't perform the chair rise test in less than $11.2 \mathrm{~s}$ and nearly half of them $(n=52)$ had SPPB scores $\leq 8$ points. A condition of osteosarcobesity or sarcoporobestiy involving all three entities was detected in as few as 8 participants (1.6\%).

The observation that muscle mass itself and muscle mass referred to body height were not very meaningful to identify subjects at risk for age-associated functional deficits is further confirmed by the finding that the annual reduction of the SMI with aging was very small with $0.29 \%$ per year. In contrast, annual decline in parameters of physical performance was as high as 1.38 , 1.52 and even $1.54 \%$ for usual gait Speed, hand grip strength and chair rise test. Even though the core finding of the annual functional decline being much more pronounced than the loss in muscle mass is in line with results form a recent publication and can be considered an independent confirmation of that finding (40), our data suggests that the loss in muscle mass is even less significant.

In line with that, neither reduced SMI $\leq 10.75 \mathrm{~kg} / \mathrm{m}^{2}$ nor age $\geq 80$ years were clinically meaningful with regards to predicting physical performance, while obesity was indicative of poor physical performance regarding lower limb function (usual gait speed, chair rise test).

\section{Conclusions}

Osteoporosis and sarcopenia and their coincidence in terms of osteosarcopenia are increasingly prevalent with progressive aging. Conversely, the proportion of obese subjects appeared stabile across various age groups and lower in the very old, making combinations of sarcopenic obesity and osteoporotic obesity less frequent. However, aging was associated with progressive functional decline of about $1.5 \%$, consistently observed in various established measures of physical performance (hand grip strength, chair rise test and usual gait speed), which was paralleled by an only marginal annual SMI decrease of $0.29 \%$. Instead of low muscle mass, osteoporosis and obesity were identified as critical determinants of functional decline. In view of this association, assessing physical performance is crucial and should be integrated in daily clinical routine not only for diagnosing sarcopenia but also for patients with osteoporosis and obesity.
This work is licensed under a Creative Commons Attribution-NonCommercial 4.0 International License. ded from Bioscientifica.com at 04/26/2023 09:56:20AM 


\section{Declaration of interest}

$\mathrm{LS}$ has received honoraria for lectures and advice from Abbvie, Amgen, Alexion, Janssen, KyowaKirin, Lilly, Medi, MSD, Novartis, Servier and UCB, research grants to the institution (University of Wuerzburg) from Alexion, Kyowa Kirin and Novartis. F G has received honoraria for lectures from Abbvie, Alexion and Lilly. M S, A Z, D L L report no COI during the course of the study.

\section{Funding}

This research did not receive any specific grant from any funding agency in the public, commercial or not-for-profit sector.

\section{Ethics approval}

The study protocol was approved by the competent ethics committee at Wuerzburg University (N. 148/13).

\section{Consent to participate}

Every participant gave written informed consent before any study related procedures.

\section{Consent to publication}

All participants gave written consent for publication.

\section{Availability of data and material}

All data and study material is stored at the Departments of Orthopedics at the University of Wuerzburg for 10 years. The datasets used and analyzed during the current study are available from the corresponding author on reasonable request.

\section{Author contribution statement}

$L$ Seefried designed and provided the study concept; acquisition of data was done by all the authors; $L$ Seefried and $F$ Genest analyzed an interpreted the data; F Genest and L Seefried drafted the manuscript; all authors did the critical revision of the manuscript for important intellectual content.

\section{Acknowledgement}

The authors acknowledge the 'Bayerische Forschungsstiftung' for supporting aspects of this project.

\section{References}

1 Melton 3rd LJ, Achenbach SJ, Atkinson EJ, Therneau TM \& Amin S. Long-term mortality following fractures at different skeletal sites: a population-based cohort study. Osteoporosis International 201324 1689-1696. (https://doi.org/10.1007/s00198-012-2225-1)

2 Haentjens P, Magaziner J, Colon-Emeric CS, Vanderschueren D, Milisen K, Velkeniers B \& Boonen S. Meta-analysis: excess mortality after hip fracture among older women and men. Annals of Internal Medicine 2010152 380-390. (https://doi.org/10.7326/0003-4819152-6-201003160-00008)

3 Hairi NN, Cumming RG, Naganathan V, Handelsman DJ, Le Couteur DG, Creasey H, Waite LM, Seibel MJ \& Sambrook PN. Loss of muscle strength, mass (sarcopenia), and quality (specific force) and its relationship with functional limitation and physical disability: the Concord Health and Ageing in Men Project. Journal of the American Geriatrics Society 201058 2055-2062. (https://doi.org/10.1111/j.15325415.2010.03145.x)

4 Woolf AD \& Pfleger B. Burden of major musculoskeletal conditions. Bulletin of the World Health Organization 200381 646-656.

5 von Haehling S, Morley JE \& Anker SD. An overview of sarcopenia: facts and numbers on prevalence and clinical impact. Journal of Cachexia, Sarcopenia and Muscle 20101 129-133. (https://doi. org/10.1007/s13539-010-0014-2)

6 Scott D, Seibel M, Cumming R, Naganathan V, Blyth F, Le Couteur DG, Handelsman DJ, Waite LM \& Hirani V. Sarcopenic obesity and its temporal associations with changes in bone mineral density, incident falls, and fractures in older men: the Concord Health and Ageing in Men Project. Journal of Bone and Mineral Research 201732 575-583. (https://doi.org/10.1002/jbmr.3016)

7 Chalhoub D, Cawthon PM, Ensrud KE, Stefanick ML, Kado DM, Boudreau R, Greenspan S, Newman AB, Zmuda J, Orwoll ES, et al. Risk of nonspine fractures in older adults with sarcopenia, low bone mass, or both. Journal of the American Geriatrics Society 201563 1733-1740. (https://doi.org/10.1111/jgs.13605)

8 Yu R, Leung J \& Woo J. Incremental predictive value of sarcopenia for incident fracture in an elderly Chinese cohort: results from the Osteoporotic Fractures in Men (MrOs) Study. Journal of the American Medical Directors Association 201415 551-558. (https://doi. org/10.1016/j.jamda.2014.02.005)

9 Di Monaco M, Castiglioni C, Vallero F, Di Monaco R \& Tappero R. Sarcopenia is more prevalent in men than in women after hip fracture: a cross-sectional study of 591 inpatients. Archives of Gerontology and Geriatrics 201255 e48-e52. (https://doi. org/10.1016/j.archger.2012.05.002)

10 Di Monaco M, Vallero F, Di Monaco R \& Tappero R. Prevalence of sarcopenia and its association with osteoporosis in 313 older women following a hip fracture. Archives of Gerontology and Geriatrics 201152 71-74. (https://doi.org/10.1016/j.archger.2010.02.002)

11 Di Monaco M, Vallero F, Di Monaco R, Tappero R \& Cavanna A. Skeletal muscle mass, fat mass, and hip bone mineral density in elderly women with hip fracture. Journal of Bone and Mineral Metabolism 200725 237-242. (https://doi.org/10.1007/s00774-0070752-1)

12 Landi F, Liperoti R, Russo A, Giovannini S, Tosato M, Capoluongo E, Bernabei R \& Onder G. Sarcopenia as a risk factor for falls in elderly individuals: results from the ilSIRENTE study. Clinical Nutrition 2012 31 652-658. (https://doi.org/10.1016/j.clnu.2012.02.007)

13 Binkley N \& Buehring B. Beyond FRAX: it's time to consider 'sarcoosteopenia'. Journal of Clinical Densitometry 200912 413-416. (https://doi.org/10.1016/j.jocd.2009.06.004)

14 Shen J, Nielson CM, Marshall LM, Lee DC, Keaveny TM, Orwoll ES \& Osteoporotic Fractures in Men MrOS Research Group. The association between BMI and QCT-derived proximal hip structure and strength in older men: a cross-sectional study. Journal of Bone and Mineral Research 201530 1301-1308. (https://doi.org/10.1002/ jbmr.2450)

15 Nielson CM, Srikanth P \& Orwoll ES. Obesity and fracture in men and women: an epidemiologic perspective. Journal of Bone and Mineral Research 201227 1-10. (https://doi.org/10.1002/jbmr.1486)

16 Compston J. Obesity and fractures in postmenopausal women. Current Opinion in Rheumatology 201527 414-419. (https://doi. org/10.1097/BOR.0000000000000182)

17 Sadeghi O, Saneei P, Nasiri M, Larijani B \& Esmaillzadeh A. Abdominal obesity and risk of hip fracture: a systematic review and meta-analysis of prospective studies. Advances in Nutrition 20178 728-738. (https://doi.org/10.3945/an.117.015545)

18 Nielson CM, Marshall LM, Adams AL, LeBlanc ES, Cawthon PM, Ensrud K, Stefanick ML, Barrett-Connor E, Orwoll ES \& Osteoporotic 
Fractures in Men Study Research Group. BMI and fracture risk in older men: the osteoporotic fractures in men study (MrOS). Journal of Bone and Mineral Research 201126 496-502. (https://doi.org/10.1002/ jbmr.235)

19 Gilsanz V, Chalfant J, Mo AO, Lee DC, Dorey FJ \& Mittelman SD. Reciprocal relations of subcutaneous and visceral fat to bone structure and strength. Journal of Clinical Endocrinology and Metabolism 200994 3387-3393. (https://doi.org/10.1210/jc.2008-2422)

20 Friedmann JM, Elasy T \& Jensen GL. The relationship between body mass index and self-reported functional limitation among older adults: a gender difference. Journal of the American Geriatrics Society 200149 398-403. (https://doi.org/10.1046/j.1532-5415.2001.49082.x)

21 Li X, Gong X \& Jiang W. Abdominal obesity and risk of hip fracture: a meta-analysis of prospective studies. Osteoporosis International 2017 28 2747-2757. (https://doi.org/10.1007/s00198-017-4142-9)

22 Fjeldstad C, Fjeldstad AS, Acree LS, Nickel KJ \& Gardner AW. The influence of obesity on falls and quality of life. Dynamic Medicine 20087 4. (https://doi.org/10.1186/1476-5918-7-4)

23 An KO \& Kim J. Association of sarcopenia and obesity with multimorbidity in Korean adults: a nationwide cross-sectional study. Journal of the American Medical Directors Association 201617960. e1-960.e7. (https://doi.org/10.1016/j.jamda.2016.07.005)

24 Lang T, Cauley JA, Tylavsky F, Bauer D, Cummings S, Harris TB \& Health ABC Study. Computed tomographic measurements of thigh muscle cross-sectional area and attenuation coefficient predict hip fracture: the health, aging, and body composition study. Journal of Bone and Mineral Research 201025 513-519. (https://doi.org/10.1359/ jbmr.090807)

25 Lang T, Streeper T, Cawthon P, Baldwin K, Taaffe DR \& Harris TB. Sarcopenia: etiology, clinical consequences, intervention, and assessment. Osteoporosis International 201021 543-559. (https://doi. org/10.1007/s00198-009-1059-y)

26 Stenholm S, Harris TB, Rantanen T, Visser M, Kritchevsky SB \& Ferrucci L. Sarcopenic obesity: definition, cause and consequences. Current Opinion in Clinical Nutrition and Metabolic Care 200811 693-700. (https://doi.org/10.1097/MCO.0b013e328312c37d)

27 Li G, Thabane L, Papaioannou A \& Adachi JD. Comparison between frailty index of deficit accumulation and fracture risk assessment tool (FRAX) in prediction of risk of fractures. Bone 201577 107-114. (https://doi.org/10.1016/j.bone.2015.04.028)

28 Cosman F, de Beur SJ, LeBoff MS, Lewiecki EM, Tanner B, Randall S, Lindsay R \& National Osteoporosis Foundation. Clinician's guide to prevention and treatment of osteoporosis. Osteoporosis International 201425 2359-2381. (https://doi.org/10.1007/s00198-014-2794-2)

29 Janssen I, Heymsfield SB, Baumgartner RN \& Ross R. Estimation of skeletal muscle mass by bioelectrical impedance analysis. Journal of Applied Physiology 200089 465-471. (https://doi.org/10.1152/ jappl.2000.89.2.465)

30 Janssen I, Baumgartner RN, Ross R, Rosenberg IH \& Roubenoff R. Skeletal muscle cutpoints associated with elevated physical disability risk in older men and women. American Journal of Epidemiology 2004 159 413-421. (https://doi.org/10.1093/aje/kwh058)

31 Cruz-Jentoft AJ, Baeyens JP, Bauer JM, Boirie Y, Cederholm T, Landi F, Martin FC, Michel JP, Rolland Y, Schneider SM, et al. Sarcopenia: European consensus on definition and diagnosis: report of the European Working Group on Sarcopenia in Older People. Age and Ageing 201039 412-423. (https://doi.org/10.1093/ageing/afq034)

32 Guralnik JM, Simonsick EM, Ferrucci L, Glynn RJ, Berkman LF, Blazer DG, Scherr PA \& Wallace RB. A short physical performance battery assessing lower extremity function: association with selfreported disability and prediction of mortality and nursing home admission. Journal of Gerontology 199449 M85-M94. (https://doi. org/10.1093/geronj/49.2.m85)

33 Kirk B, Zanker J \& Duque G. Osteosarcopenia: epidemiology, diagnosis, and treatment - facts and numbers. Journal of Cachexia, Sarcopenia and Muscle 202011 609-618. (https://doi.org/10.1002/ jcsm.12567).

34 Kirk B, Al Saedi A \& Osteosarcopenia DG. A case of geroscience. Aging Medicine 20192 147-156. (https://doi.org/10.1002/agm2.12080)

35 Bowman K, Atkins JL, Delgado J, Kos K, Kuchel GA, Ble A, Ferrucci L $\&$ Melzer D. Central adiposity and the overweight risk paradox in aging: follow-up of 130,473 UK Biobank participants. American Journal of Clinical Nutrition 2017106 130-135. (https://doi. org/10.3945/ajcn.116.147157)

36 Zembron-Lacny A, Dziubek W, Wolny-Rokicka E, Dabrowska G \& Wozniewski M. The relation of inflammaging with skeletal muscle properties in elderly men. American Journal of Men's Health 201913 1557988319841934. (https://doi.org/10.1177/1557988319841934)

37 Ponti F, Santoro A, Mercatelli D, Gasperini C, Conte M, Martucci M, Sangiorgi L, Franceschi C \& Bazzocchi A. Aging and imaging assessment of body composition: from fat to facts. Frontiers in Endocrinology 201910 861. (https://doi.org/10.3389/ fendo.2019.00861)

38 Bachasson D, Ayaz AC, Mosso J, Canal A, Boisserie JM, Araujo ECA, Benveniste O, Reyngoudt H, Marty B, Carlier PG, et al. Lean regional muscle volume estimates using explanatory bioelectrical models in healthy subjects and patients with muscle wasting. Journal of Cachexia, Sarcopenia and Muscle 202012 39-51. (https://doi. org/10.1002/jcsm.12656)

39 Bauer JM, Cruz-Jentoft AJ, Fielding RA, Kanis JA, Reginster JY, Bruyere O, Cesari M, Chapurlat R, Al-Daghri N, Dennison E, et al. Is there enough evidence for osteosarcopenic obesity as a distinct entity? A critical literature review. Calcified Tissue International 2019 105 109-124. (https://doi.org/10.1007/s00223-019-00561-w)

40 Westbury LD, Syddall HE, Fuggle NR, Dennison EM, Cauley JA, Shiroma EJ, Fielding RA, Newman AB \& Cooper C. Long-term rates of change in musculoskeletal aging and body composition: findings from the Health, Aging and Body Composition Study. Calcified Tissue International 2020106 616-624. (https://doi.org/10.1007/s00223020-00679-2)

Received in final form 4 January 2021

Accepted 18 January 2021

Accepted Manuscript published online 22 January 2021 https://ec.bioscientifica.com https://doi.org/10.1530/EC-20-0580 (c) 2021 The authors Published by Bioscientifica Ltd

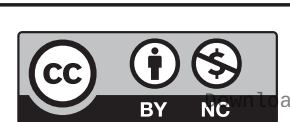

This work is licensed under a Creative Commons Attribution-NonCommercial 4.0 International License. ded from Bioscientifica.com at 04/26/2023 09:56:20AM 